\title{
FREUD E A TEORIA DA INTERPRETAÇÃO DOS SONHOS: UMA DISCUSSÃO À LUZ DA FILOSOFIA DE MARTIN HEIDEGGER E DE PAUL RICOEUR
}

\author{
Fernanda de Jesus Almeida 1; Caroline Vasconcelos Ribeiro 2 \\ 1:Bolsista PIBIC-AF\CNPq, Graduanda em Psicologia, Universidade Estadual de Feira de Santana,e-mail: \\ fernanda.uefs2011@ hotmail.com. \\ 2: Orientadora: $\mathrm{Dr}^{\mathrm{a}}$ Caroline Vasconcelos Ribeiro, Departamento de Ciências Humanas e Filosofia, Universidade \\ Estadual de Feira de Santana, e-mail: carolinevasconcelos@ hotmail.com
}

\section{PALAVRAS-CHAVE: Formação dos sonhos; Heidegger; Ricoeur. INTRODUÇÃO}

O presente resumo expandido almeja apresentar os resultados obtidos com a execução de um ano de pesquisa, na modalidade de iniciação científica, cujo apoio institucional foi do Conselho Nacional de Desenvolvimento Científico e Tecnológico (CNPq). A pesquisa, intitulada "Freud e a teoria da interpretação dos sonhos: uma discussão à luz da filosofia de Martin Heidegger e de Paul Ricoeur", teve como finalidade investigar se a teoria freudiana da interpretação dos sonhos se afina com as formulações das ciências naturais, como advoga Martin Heidegger, ou se, devido ao fato de buscar decifrar os sentidos dos conteúdos oníricos, se afasta do naturalismo, como afirma Paul Ricoeur.

Ricoeur (1977) defende, na obra Da interpretação: um ensaio sobre Freud, que, ao interpretar os sonhos, a psicanálise não só revelou que os mesmo têm sentidos, mas demonstrou que tais sentidos são deslocados e distorcidos na forma representativa de imagens. De acordo com a perspectiva ricoeuriana, a busca dos sentidos ocultos dos sonhos é um procedimento que não pode ser encaixado no rol de procedimentos puramente naturalistas. Para o filósofo francês, com a busca dos sentidos latentes dos sonhos Freud se desvinculou da supremacia da explicabilidade naturalista presente em seu escrito inicial intitulado Projeto para uma psicologia científica, de 1895.

Na obra Seminários de Zollikon Martin Heidegger (2001) atesta que Freud postula o conceito de inconsciente a favor da explicabilidade de todos os atos psíquicos - inclusive a formação dos sonhos -, se servindo de pressupostos oriundos das ciências naturais. De acordo com Freud a etiologia da elaboração onírica é atribuída ao inconsciente, ou seja, "a força propulsora da formação dos sonhos é fornecida pelo inconsciente" (FREUD, 1996a, p. 568). Para Heidegger, na medida em que este constructo cumpre função causal, não deve ser considerado como um elemento desvinculado do naturalismo. Pretendemos com este resumo expandido explanar e problematizar, dentro do escopo a ele atribuído, a posição dos autores frente à teoria freudiana da elaboração dos sonhos.

\section{MATERIAL, MÉTODOS OU METODOLOGIA (ou equivalente)}

A metodologia empregada para a elaboração da pesquisa foi de cunho bibliográfico; sua tarefa central consistiu numa leitura de fontes primárias - Heidegger, Freud e Ricoeur - e de comentadores. O passo inicial consistiu na leitura de textos freudianos, dentre os quais destacamos: A interpretação dos sonhos (1996a), Projeto para uma psicologia científica (1996b), Algumas lições elementares de psicanálise (1996c), Esboço de psicanálise (1996d), Um estudo autobiográfico (1996e), Novas conferências introdutórias sobre a psicanálise. Conferência XXIX: Revisão da teoria dos sonhos (1996f), O Inconsciente (2006a), Suplemento metapsicológico à teoria dos sonhos (2006b) e Repressão (2006c). Durante toda a pesquisa utilizamos o Vocabulário de Psicanálise, de Laplanche e Pontalis (2001) e o livro As palavras de Freud: Vocabulário freudiano e suas versões (2010) de Paulo Cesar Souza. Em relação aos argumentos heideggerianos utilizamos a obra Seminários de Zollikon (2001) e parágrafos de Ser e Tempo (2005), além de capítulos das obras: Nietzsche II (2007); "Que é metafísica?" (1983) e Carta sobre o humanismo (2009). De Paul Ricoeur lemos e discutimos a obra Da interpretação: ensaio sobre Freud (1977); além disso, nos servimos do livro 
Hermenêutica e psicanálise na obra de Paul Ricoeur de Sérgio Franco. O passo seguinte consistiu na leitura de textos de epistemólogos da psicanálise: Monzani, Assoun, Garcia-Roza Fulgencio e Loparic. Para o estudo do programa kantiano para a ciência da natureza fizemos a leitura de capítulos da obra: Princípios metafísicos da ciência da natureza (KANT,1990) sempre cotejando com o Dicionário Kant (2000) de Howard Caygill. Como passo metodológico final, fizemos a discussão dos artigos: De Kant a Freud: um roteiro (2003a) e As duas metafísicas de Kant (2003b) de Zeljko Loparic, Comentários críticos das referências textuais de Freud a Kant (2001) de Leopoldo Fulgencio, "Que tipo de ciência é, afinal, a psicanálise?” de Renato Mezan (2007) e Freud e o Methodenstreit: um debate a partir dos Seminários de Zollikon de Caroline V. Ribeiro (2014).

\section{RESULTADOS E/OU DISCUSSÃO (ou Análise e discussão dos resultados)}

Em A Interpretação dos sonhos Freud (1996a) apresenta ao leitor a concepção de um aparelho psíquico sem referências anatômicas, concebido "psicologicamente", composto por instâncias psíquicas e não mais por neurônios investidos, como na obra Projeto para uma psicologia científica (FREUD, 1996b). Das instâncias psíquicas presentes no aparelho a de maior relevância para nosso trabalho é o inconsciente, pois é nela que o sonho, assim como todo processo psíquico, é formado. É sobre esse conceito e sua função causal na formação dos atos psíquicos que repousa a crítica de Heidegger à psicanálise de Freud.

Na obra Da interpretação: ensaio sobre Freud Ricoeur (1977, p.68) argumenta que, "de ponta a ponta, a psicanálise é interpretação". Segundo o autor em comento quando o analista faz a decifração dos sentidos ocultos das manifestações psíquicas está a exercer a desmitificação, afinal, destrona o lugar da consciência em favor da decodificação de signos cifrados oriundos do inconsciente. Segundo Ricoeur com a obra A interpretação dos sonhos que Freud concebe uma virada no campo do discurso da psicanálise, afinal, a exegese de sentidos se sobrepõe à explicação energetista do funcionamento psíquico, típica do começo das pesquisas freudianas. Esta virada conferiria à psicanálise um discurso misto e não puramente naturalista. Para Ricoeur o sonho é um trabalho "que requer, para tematizar-se, uma linguagem mista que não seja nem puramente linguística, nem puramente energética". (RICOEUR, 1977, p. 88).

O pensamento de Heidegger em relação à psicanálise freudiana aponta para outra direção. Segundo o filósofo alemão o fato de ter postulado um conceito abstrato como o de "inconsciente" não impugna a tentativa de explicabilidade típica das ciências naturais. Heidegger nos lembra que o uso de ficções e convenções para organizar os dados oriundos da experiência empírica é avalizado pelo programa de pesquisa kantiano para as ciências da natureza. Em função disso, afirma que Freud se serve do horizonte de pesquisa de molde kantiano para formulação de sua ciência. O conceito metapsicológico "inconsciente" funciona, na perspectiva heideggeriana, como uma ideia abstrata da razão que serve para organização de dados empíricos. Para Heidegger (2001), Freud se serve de pressupostos herdados das ciências naturais para sistematizar seu conceito de inconsciente e, consequentemente, sua teoria da elaboração onírica, já que o inconsciente é postulado como elemento causal dos sonhos. De acordo com Freud, a vida anímica inconsciente é a grande mola produtora de fenômenos psíquicos, tais como os sonhos, sintomas, atos falhos. Segundo Heidegger, o pai da psicanálise postula o conceito de inconsciente com o fito de tornar todos os fenômenos psíquicos explicáveis, com o objetivo de designar-lhes uma causa. Ainda que fale de decifração de sonhos e de interpretação de sintomas não há, na perspectiva heideggeriana, uma ruptura com as pretensões de explicabilidade cativas à postura científiconatural, posto que a decifração e interpretação são feitas em busca do preenchimento de todas as conexões causais que determinaram a produção do processo psíquico.

\section{CONCLUSÃO}


Em relação ao processo de formação e interpretação dos sonhos, Ricoeur advoga pela submissão da explicação em relação à interpretação, posto que é a interpretação que comanda a teoria da elaboração onírica. Na perspectiva ricoeuriana, ainda que haja uma explicação, a mesma não é equivalente à existente no escrito Projeto para uma psicologia científica cuja marca era a presença de um discurso naturalista, vinculado à neurologia. Para o autor em comento o naturalismo presente neste escrito perde o lugar a partir da obra freudiana $A$ Interpretação dos Sonhos, na qual a explicação de caráter energetista e a interpretação andariam de mãos dadas. A posição de Ricoeur (1977, p. 73) acerca da psicanálise freudiana consiste em identificá-la como um campo de saber que, por lidar com sentidos ocultos dos sonhos e demais formações inconscientes, aproxima-se de uma hermenêutica. Ao conduzirmos nossas investigações, notamos que a análise de Ricoeur parece não ter levado em consideração a natureza metapsicológica do conceito de inconsciente, tal como apontada por Heidegger. Os argumentos heideggerianos indicam que o conceito de inconsciente é formulado com base nos princípios kantianos para a ciência natural, ou seja, indicam que este conceito abstrato é heuristicamente usado para ordenar dados clínicos e fornecer explicabilidade ao psiquismo. Esse tipo de utilização de ideias abstratas - de convenções com valor heurístico - é preconizado por Kant na obra Princípios metafísicos da ciência da natureza. Como o sonho é um produto da ação do inconsciente, a sua decifração - na perspectiva heideggeriana - equivale a uma busca das causas que atuam em sua produção. Ao visar detectar as causas inconscientes da formação onírica Freud estaria se servindo de um procedimento afinado à explicabilidade cativa às ciências da natureza. Vimos, com o desenrolar de nossa investigação, que não apenas Heidegger destaca este aspecto da teoria freudiana sobre os sonhos, mas também comentadores e epistemólogos da Psicanálise. Assoun, por exemplo, afirma que "determinar a significação (Bedeutung) do sonho não significa jamais, em Freud, desmantelar o esquema causal" (ASSOUN, 1983, p. 50). O fato de ter abandonado o aparelho neuronal no escrito Projeto para uma psicologia científica e formulado um aparelho de caráter especulativo na obra $A$ Interpretação dos sonhos, não equivale, na perspectiva de Heidegger, a adoção de um discurso misto. Podemos dizer, à luz das discussões, que o intuito de Freud não era harmonizar os conteúdos energéticos com os qualitativos - como advoga Ricoeur - mas "produzir um constructo esquemático - poder-seia, também, dizer metafórico - que fosse útil, tal como as ficções heurísticas de Kant, para a resolução de problemas médicos específicos" (LOPARIC, 2003a, p.11). Ao fim de nossa pesquisa chegamos à conclusão de que não é fácil sustentar, como defende Ricoeur, que o energetismo naturalista cedeu um vasto lugar para os elementos hermenêuticos na teoria freudiana da interpretação dos sonhos. À luz de Heidegger e de comentadores da psicanálise concluímos que a formulação acerca da formação onírica, ao visar apontar as causas inconscientes, aproxima a psicanálise freudiana da identidade científico-natural.

\section{REFERÊNCIAS}

ASSOUN, P-L. Introdução à epistemologia freudiana. Tradução: Hilton Japiassu. Rio de Janeiro: Imago, 1983.

CAYGILL, Howard. Dicionário Kant. Tradução: Álvaro Cabral: revisão técnica, ValerioRohden. Rio de Janeiro: Jorge Zahar. Ed., 2000.

FRANCO, Sérgio de Gouvêa. Hermenêutica e Psicanálise na obra de Paul Ricoeur. São Paulo: Loyola, 1995.

FREUD, S. "A Interpretação dos sonhos". In Edição Standard brasileira das obras completas de Sigmund Freud. Rio de Janeiro: Imago Editora, 1996a. Vol. V.

FREUD, S. "Projeto para uma psicologia científica". In: Edição Standard brasileira das obras completas de Sigmund Freud. Rio de Janeiro: Imago Editora, 1996b. Vol. I. 
FREUD, S. “Algumas lições elementares de psicanálise”. In: Edição Standard brasileira das obras completas de Sigmund Freud. Rio de Janeiro: Imago Editora, 1996c. Vol. XXIII.

FREUD, S. "Esboço de psicanálise". In: Edição Standard brasileira das obras completas de Sigmund Freud. Rio de Janeiro: Imago Editora, 1996d. Vol. XXIII.

FREUD, S. "Um estudo Autobiográfico". In: Edição Standard brasileira das obras completas de Sigmund Freud. Rio de Janeiro: Imago Editora, 1996e, Vol. XX.

FREUD, S. "Novas conferências introdutórias sobre a psicanálise. Conferência XXIX: Revisão da teoria dos sonhos". In: Edição Standard brasileira das obras completas de Sigmund Freud. Rio de Janeiro: Imago Editora, 1996f. Vol. XXII.

FREUD, S. "O Inconsciente”. In: Obras psicológicas completas de Sigmund Freud. Tradução de Luiz Alberto Hanns. - Rio de Janeiro: Imago Editora. Vol. II, pp.14 - 74, 2006 a.

FREUD, S. "Suplemento metapsicológico à teoria dos sonhos" In: Obras psicológicas completas de Sigmund Freud. Tradução de Luiz Alberto Hanns. - Rio de Janeiro: Imago Editora. Vol. II, pp.75 - 98, 2006b.

FREUD, S. "O recalque” In: Obras psicológicas completas de Sigmund Freud. Tradução de Luiz Alberto Hanns. - Rio de Janeiro: Imago Editora. Vol. II, pp.75 - 98, 2006c.

HEIDEGGER, M. Seminários de Zollikon. Tradução brasileira: Maria de Fátima Almeida Prado, Gabriela Arnhold, São Paulo: EDUC; Petrópolis: Vozes, 2001.

HEIDEGGER, M. Nietzsche II. Tradução de Marco Antônio Casanova. Rio de Janeiro: Forense Universitária, 2007.

HEIDEGGER, M. Ser e Tempo. Tradução e notas Márcia de Sá Cavalcante. Petrópolis: Vozes, 2005.

HEIDEGGER, M. “Que é metafísica?” In: Conferências e escritos filosóficos. Tradução, introduções e notas de Ernildo Stein. São Paulo: Abril Cultural, 1983.

HEIDEGGER, M. Carta sobre o humanismo. Introdução, tradução e notas de Emmanuel Carneiro Leão. 3. ed. Rio de Janeiro: Edições Tempo Brasileiro, 2009.

KANT, Immanuel. Princípios metafísicos da ciência da natureza. Tradução de Artur Morão. Rio de Janeiro: Edições 70, 1990. [247p.]

FULGENCIO, L. “As especulações metapsicológicas de Freud” in: Natureza Humana. São Paulo: EDUC, vol. 5.n 1, 2003.

FULGENCIO, L. "Comentários críticos das referências textuais de Freud a Kant". In: Psicologia USP, Vol. 12, N. 1, 49-87, 2001.

FULGENCIO, L. O método especulativo em Freud. São Paulo: EDUC, 2008.

GARCIA-ROZA, L. Introdução à metapsicologia freudiana, v.1. Sobre as afasias (1891): O projeto de 1895. Rio de Janeiro: Jorge Zahar Ed., 1991.

LAPLANCHE, J. E PONTALIS, J.B. Vocabulário da Psicanálise. Tradução: Pedro Tamen. São Paulo: Martins Fontes, 2001.

LOPARIC, Z. "Além do Inconsciente - sobre a desconstrução heideggeriana da psicanálise". In: Natureza Humana. São Paulo: EDUC, vol. 3.n 1, 2001.

LOPARIC, Z. "De Kant a Freud: um roteiro". In: Kant e-Prints - Vol. 2, n. 8, 2003a.

LOPARIC, Z. "As duas metafísicas de Kant" in: Kant e-prints, vol2, n 5. $2003 \mathrm{~b}$.

MEZAN, R. "Que tipo de ciência é, afinal, a psicanálise?" In: Natureza - Revista Internacional de Filosofia e Psicanálise. São Paulo: EDUC, vol. 9, nº 2, 2007.

MONZANI, L, R. Freud: o movimento de um pensamento. Campinas: Editora Unicamp, 1989.

RIBEIRO, C.V. "Freud e o Methodenstreit: um debate a partir dos Seminários de Zollikon" in: Diálogos Possíveis. Salvador: vol13, n.2, 2014

RICOEUR, P. Da interpretação: ensaio sobre Freud. Rio de Janeiro: Imago Editora, 1977.

SOUZA, P. C. As palavras de Freud: vocabulário freudiano e suas versões. São Paulo: Companhia das Letras, 2010. 